\title{
D. Warwick, R. Dunn, E. Melikyan, J. Vadher: Hand Surgery
}

\author{
Oxford University Press, Oxford, 2009, 635 pp, ISBN 978-0-19-922723-5, \$35
}

\section{Leo Clodius}

Received: 15 January 2011 / Accepted: 15 January 2011 /Published online: 12 February 2011

(C) Springer-Verlag 2011

The four authors are frontrunners in hand surgery and in rehabilitation of the hand. They have produced a pocketsized, handy, flexible volume, easily carried. The 634 pages demonstrate excellent teamwork for optimal results. This teamwork tradition began with the incorporation of hand rehabilitation and the referring surgeons: Guy Pulvertraft, Paul Brand, Kit Wynn-Parry are responsible for many excellent groups today. Thus, this flexible manual will be welcomed especially by surgeons in this field and by physiotherapists alike - as an aide memoire to beginners as well as to the experienced, and also an excellent teaching tool.
The contents of this book are divided into 18 chapters: Assessment, Rehabilitation, Anesthesia, Bone and Joint Injuries-Wrist and Forearm, Bone and Joint Injuries of the Hand, Reconstruction, Skin Conditions, Osteoarthritis of the Hand, Infection, Nerves, Rheumatology, Tendons, Ulnar Corner, Wrist, Children, Tumors, and Vascular.

Looking for a detail, you may find it in the 11 pages of the index.

This reviewer considers this almost indispensible guide a fascinating help for hand surgeons, plastic surgeons, hand therapists and for GPs, as it is concise, comprehensive, and provides the best therapy in this challenging field of therapy.

L. Clodius $(\square)$ 